\title{
From BAT (best available technique) to BCAT (best combination of available techniques)
}

Th Bréchet and H. Tulkens

Discussion Paper 2006-60

\section{Département des Sciences Économiques de l'Université catholique de Louvain}




\title{
From BAT (best available technique) to BCAT (best combination of available techniques)
}

\author{
Thierry Bréchet* and Henry Tulkens ${ }^{\dagger}$
}

November 5, 2006

\begin{abstract}
Technological choices are multi-dimensional and thus one needs a multidimensional methodology to identify best available techniques. Moreover, in the presence of environmental externalities generated by productive activities, 'best' available techniques should be best from Society's point of view, not only in terms of private interests. In this paper we develop a comprehensive modeling tool, based on methodologies appropriate to serve these two purposes, namely linear programming and internalization of external costs. We conclude that in this context there is in general not a single best available technique (BAT), but well a best combination of available techniques to be used (BCAT).

We take a fictitious but plausible numerical example in the lime industry. For a hypothetical plant that has to meet a given demand, we build an original technical economic model within which two scenarios are considered: minimizing the private costs and minimizing the generalized costs (private costs plus external costs). In the first case, only the cheapest fuel is used in all kilns. But in the second case,
\end{abstract}

${ }^{*}$ Center for Operations Research and Econometrics (CORE) and Louvain School of Management, Chair Lhoist Berghmans in Environmental Economics and Management, Université catholique de Louvain.

†Center for Operations Research and Econometrics (CORE), Université catholique de Louvain. 
where the environmental external costs are included, fuel switches occur and cleaner techniques are used. Extending the analysis to the choice of kilns, we find that the socially best combination of available techniques (S-BCAT) is not a fixed one : it varies as a function of the external costs. We therefore trace in a single diagram the whole profile of these best techniques as successive solutions of our linear programs. We conclude by stressing that external cost internalization does influence not only the choice of techniques, but also their appropriate use. Moreover, local environmental conditions play a major role in that choice and in determining that use.

Keywords: best available techniques, eco-efficiency, IPPC

JEL codes: D20; Q50

Acknowledgments: The authors are grateful to Gérard Flament and Thomas Schlegel for fruitful discussions. They also thank Marion Courtois and, especially, to Johan Lepers for computational support and editing. 


\section{Contents}

1 Introduction $\quad 4$

1.1 Single vs. multiple techniques . . . . . . . . . . . . 4

1.2 The choice of a criterion: minimizing private as well as environmental costs . . . . . . . . . . . . . . . . . 6

$\begin{array}{lll}2 & \text { A brief review of the BAT literature } & 7\end{array}$

$\begin{array}{llr}3 & \text { The industrial activity } & 8\end{array}$

4 Definitions $\quad \mathbf{1 0}$

4.1 Indexes . . . . . . . . . . . . . . . . . . . . . . 10

4.2 Variables . . . . . . . . . . . . . . . . . . . 10

4.3 Parameters ..................... 11

5 The model 12

6 Numerical values of the parameters $\quad 15$

7 The results (1): selecting a BCAT $\quad 17$

7.1 BCAT that minimizes private costs (P-BCAT) . . . . . . . 18

7.2 BCAT that minimizes generalized costs (S-BCAT) . . . . . . 20

7.3 Sensitivity analysis ................. . . 22

8 The results (2): BCATs as a function of external costs 24

9 Conclusion $\quad 27$ 


\section{Introduction}

One of the cornerstones of the European Commission's environmental protection policy today is the implementation of some best available techniques (BAT) in industrial activities. Leaving aside the issue of whether technological choices are to be made by industry or by public administrations, this paper focuses on the preliminary question of the identification of a best technique. The Integrated Pollution Prevention and Control (IPPC, hereafter) Directive defines BATs as technologies and organizational measures expected to minimize overall environmental pressures at acceptable private costs. The purpose of the Directive (European Commission, 1996) is to achieve integrated prevention and control of pollution arising from industrial activities. The Directive includes operating permits for industrial installations based on BAT. Quoting the Directive, a BAT is defined as follows:

1. 'techniques' shall include both the technology used and the way in which the installation is designed, built, maintained, operated and decommissioned,

2. 'available' techniques shall mean those developped on a scale which allows implementation in the relevant industrial sector, under economically and technically viable conditions, taking into consideration the costs and the advantages,

3. 'best' shall mean most effective in achieving a high level of protection of the environment as a whole.

The IPPC Directive is a major piece of environmental regulation, covering around 55,000 installations in the EU. According to the European Pollutant Emission Register (EPER), these installations were responsible for $70 \%$ of the emissions of sulphur oxides and for $42 \%$ of the emissions of carbon dioxide in the EU-15 in 2001.

\section{$1.1 \quad$ Single vs. multiple techniques}

Further examination of the Directive and of its application leads one to observe that, in spite of the plural used in the just quoted definition, the regula- 
tory effort focuses on identifying a single technique in each sector, declared to be best on the criterion consisting in maximizing environmental protection, subject to economic and technical viability. An illustrative example is given in the lime industry where a specific kiln (PFR) and a specific fuel (gas) have been selected as the best available technique. The observation of industrial practice, however, leads one to conclude that it is not only impractical but also inefficient, both environmentally and economically, to formulate the desirable course of action of industry in terms of a single technique in each sector. When various techniques exist in industrial life, each one of them has historical or technical justifications, due to characteristics that may - or may not anymore - contribute validly to the realization of the desired output. The relevant question then is how to combine these techniques in the best way, without a priori restricting this combination to only one of them.

In the meantime, during the 90s, the European Commission has developed the ExternE methodology to evaluate social and environmental damages due to polluting activities in monetary terms. Yet, this methodology is not used when determining the BAT. Data concerning costs of available techniques are provided in the IPPC reference documents called BREFs ${ }^{1}$, but only given as a rough indicators of the magnitude of the costs involved.

Our aim in this paper is twofold. First, technological choices being multidimensional, one needs a multi-dimensional methodology to identify best combinations of available technologies. Secondly, we have recourse to economically grounded monetary valuations of environmental costs in selecting the best technique. Hence, our contribution consists in developing a comprehensive modelling tool based on these two methodologies so as to provide a better justified way to choose among available techniques.

We propose to identify such best combination of technologies as the solution of a linear programming model. Linear programming is a classical mathematical model of production activities that has a long history, both

\footnotetext{
${ }^{1}$ BREFs stands for Bat REFerence documents, which are sector-specific in the IPPC directive.
} 
theoretical and applied. It recognizes from the start the variety of alternatives - and it even allows for changes in that variety. This methodology is of general nature and, per se, independent of both BAT and environmental issues. It has been applied in many sectors ${ }^{2}$.

We take as an example the particular case of the lime industry ${ }^{3}$. The properties of the model do not exclude that its solution eventually recognizes a single technique as the optimal one. But this will generally not be the case, due to the nature of the inherently varied components of the industrial problem under study.

\subsection{The choice of a criterion: minimizing private as well as environmental costs}

While maximizing environmental protection is a respectable objective, we consider in this paper that the constraint of technical and economic viability is an ill defined one, at least in its economic component. Indeed, what are the limits of economic feasibility? Zero profit? Bankruptcy threshold? In a market economy, no industrial firm can be seriously considered being run on such a basis.

Classical microeconomic reasoning has been suggesting instead, for decades, the profit maximization criterion. And no less classical theorems in welfare economics have established the extent to which this criterion is compatible with the public interest in market economies. The recent emergence of environmental economics, also concerned with the public interest, has changed this basic behavioral criterion of firms, not in its nature (profit), but well in its choice of the cost component of profit. It recommends that environmental concerns be taken into consideration by introducing them as social (or external) costs added up to the usual private (internal) cost of any firm, the two components thus forming what is often called generalized cost. In the same spirit, environmental economics recommends that when a firm's

\footnotetext{
${ }^{2}$ e.g. electricity, transportation, postal services, telecommunications, oil refining,...

${ }^{3}$ for which we build an original linear programming model, as we are not aware of any published such linear programming model
} 
behavior is modeled in terms of total cost minimization subject to satisfying a given demand, total cost be understood as including, besides usual accounting (thus private) costs, the social (or external) cost of all forms of environmental damages entailed by the productive activity.

This is the approach we develop in this paper. The socially best combination of available techniques ( $S$-BCAT) that we seek to identify will be those which minimize the generalized total cost just defined.

The article proceeds as follows. In Section 2 we survey the current methodologies used to select the BAT. Section 3 briefly presents the industry activity (lime industry) to which we will apply our methodology. Then, in Sections 4 and 5, the LP model is described, and the numerical values of the parameters are given in Section 6. Section 7 shows how this framework allows one to define the BCATs, and Section 8 presents a generalization, showing how BCATs are function of external costs. Section 9 concludes.

\section{A brief review of the BAT literature}

Under the pressure of the IPPC directive two main methodologies have been put forward and used to select BATs ${ }^{4}$, the BREF cross-media methodology (Geldermann, 2000) and the VITO $^{5}$ methodology (Dijkmans, 2000), Vercaemst (2002)). These two methodologies are quite similar. Their objective is to face the issue of technique selection through a pragmatic procedure. The first one played a role in the way in which the information is presented in the BREFs. The BREFs documents are designed to help national policy-makers determine BATs and BAT-based emission limits.

The VITO has developed its own methodology to select the BAT at the industry level with a stepwise procedure. The first step is the identification

\footnotetext{
${ }^{4}$ The concept of BATNEEC (Best Available Technique Not Entailing Excessive Costs) may also be met in the literature (Pearce, 1993)

${ }^{5}$ Vlaamse Instelling voor Technologisch Onderzoek, the Flemish Institute for Technological Research.
} 
of the key environmental issues and the collection of a list of candidateBAT techniques. The second step analyzes the technical feasibility of the techniques. If the technique is not feasible, it cannot be a candidate-BAT; otherwise, it can. The third step evaluates the overall environmental benefits related to the implementation of the candidate-BAT under analysis. If there are no clear environmental benefits the technique is rejected. The fourth step consists in analyzing the economic feasibility of the selected technique. A candidate-BAT is considered as economically acceptable if $(i)$ it is feasible for an average, well managed company of the sector and (ii) if the ratio between costs and environmental benefits is not unreasonable. Economic feasibility is calculated by VITO with a non optimization tool called the MIOW+ model (see Dijkmans, 2000).

When implementing this methodology, it turns out that most of the remaining BAT-options are not mutually exclusive. In other words, the implementation of a specific candidate-BAT does not exclude the use of another one (although some candidate-BATs are mutually exclusive at the process level). Indeed, several techniques often have close environmental benefits, and are all rated ' + ' in the BAT evaluation table, so that no choice can be recommended at the sectorial level.

\section{The industrial activity}

We now move to the formulation of a model of industrial activity, specific to a firm of the lime industry, which illustrates the approach we advocate for identifying BCATs. We consider a single plant, comprising a quarry with a stone crushing station and several kilns of given capacity, producing given quantities of final products of various qualities and emitting various kinds of pollutants. Let us briefly describe the lime production process, as represented in Figure 1.

The raw material for lime production is limestone. Only high purity limestone is quarried. The unused stone goes directly to the landfill. Limestone is crushed to the appropriate size range, from 2 to $150 \mathrm{~mm}$ depending on the kiln used. The burning of the limestone is necessary to liberate carbon 


\section{Lime Production Flow Chart}

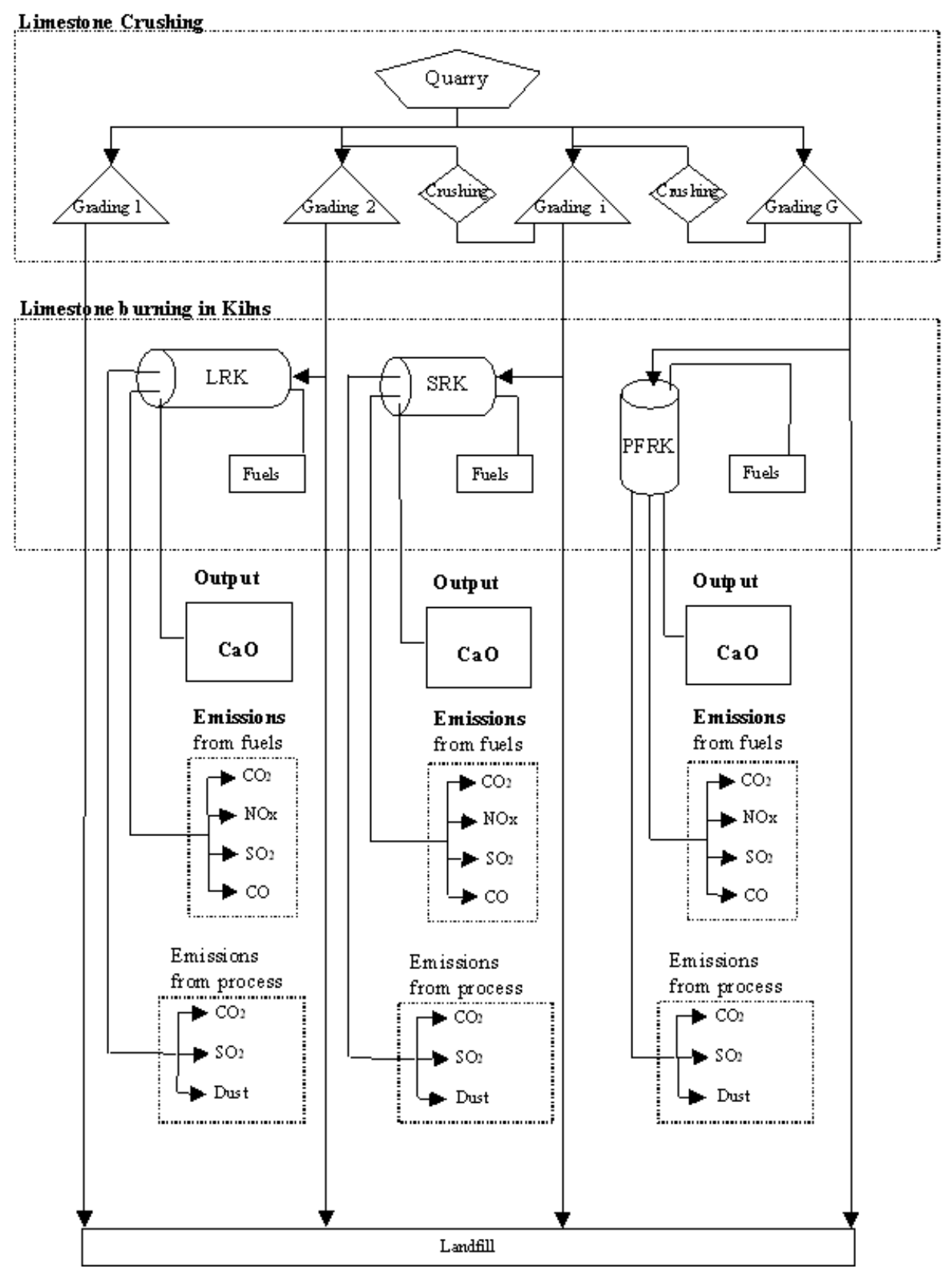

Figure 1: Overview of a lime production process 
dioxide and to obtain the derived oxide $\left(\mathrm{CaCO}_{3} \rightarrow \mathrm{CaO}+\mathrm{CO}_{2}\right)$. The temperature required is between 1000 and $1200^{\circ} \mathrm{C}$. The energy is provided by many fuels: gas, liquid and solid. Most kilns can operate with more than one fuel, but some fuels cannot be used in some kilns. A large variety of kilns is also potentially available. We assume that the producer can choose between six types of kilns. The main differences between these kilns is that some are more energy-efficient, and they do not accept all sizes of limestone. Dust appears during the process, some of which is recovered and sold while the rest goes to the landfill.

\section{Definitions}

\subsection{Indexes}

The following indexes are defined.

$$
\begin{aligned}
& k \in\{1, \ldots K\}: \text { kiln types (LRK, SRK, FLMK, PFRK, NSK, ASK) } \\
& g \in\{1, \ldots G\}: \text { granular categories ( } 1 \text { to } 9) \\
& l \in\{1, \ldots L\}: \text { quality categories of final output } \\
& f \in\{1, \ldots F\}: \text { fuel types (Gaseous, Liquid, Lignite, Petcoke, Coal, others) } \\
& p \in\{1, \ldots P\}: \text { pollutants }\left(\mathrm{NO}_{x}, \mathrm{SO}_{2}, \mathrm{CO} \text { and } \mathrm{CO}_{2}\right)
\end{aligned}
$$

\subsection{Variables}

All variables are flow variables expressed in tons per year, except for $x_{f, k}$, which is expressed in $T J$ per year.

We consider the following endogenous variables:

$n$ : gross material flow from the quarry after explosion

$q$ : flow of limestone from the quarry

$u_{g}:$ limestone flow of granular $g$

$v_{g}$ : amount of thin stone useless for lime production, going to the landfill

$u_{g+1, g}$ : amount of crushed stone (from granular $g+1$ to granular $g$ )

$y_{g, k}:$ amount of limestone of granular $g$ entering kiln $k$

$x_{f, k}$ : energy input of fuel $f$ in kiln $k$ (in $T J / y e a r$ )

$z_{k, l}$ : amount of quicklime of quality $l$ exiting kiln $k$ 
$w_{k}^{p}$ : amount of pollutant of type $p$ emitted by kiln $k$

$w_{k}^{d}$ : amount of dust leaking from kiln $k$

We define $G T O C\left(D_{l} ; \bar{y}\right)$ as the Generalized Total Operating Cost (expressed in Euros/year) of delivering a given demand level $D_{l}$, from a plant of capacity $\bar{Y}$, where these two magnitudes are parameters to be defined below.

\subsection{Parameters}

The parameters and exogenous variables of the model are the defined and denoted as follows:

- Demand to be satisfied:

$D_{l}$ : quicklime demand of quality $l$ (tons of $\mathrm{CaO} /$ year)

- Quarry and material flows characteristics:

$N^{\max }$ : maximum gross material flow from the quarry

$\lambda$ : proportion of gross flow from the quarry available for lime production

$\alpha_{g}$ : granular distribution of quarry's gross flow $\left(0 \leq \alpha_{g} \leq 1, \forall g\right.$, with $\left.\sum \alpha_{g}=1\right)$

- Technologies:

$\bar{Y}_{k}$ : limestone input capacity of kiln $k$

$\bar{Y}=\left(\bar{Y}_{1}, \ldots, \bar{Y}_{K}\right)$ : vector of kiln capacities

$\Omega_{g, k}$ : acceptability of limestone of grading $g$ in kiln $k$ ( $1=$ yes, $0=$ no)

$\Psi_{f, k}$ : acceptability of fuel $f$ in kiln $k(1=$ yes, $0=$ no)

$\Phi_{k, l}$ : capacity of kiln $k$ to produce quality $l(1=$ yes, $0=$ no)

- Environmental parameters:

$\varepsilon_{k}$ : energy efficiency of kiln $k(t C a O / T J)$

$\rho_{f}^{p}$ : emission rate for pollutant $p$ from fuel $f(t / T J)$ 
$\rho_{k}^{p}$ : emission rate for pollutant $p$ from kiln $k(t / t$ limestone)

$\eta_{k}$ : dust emission rate of kiln $k$

$\xi$ : proportion of dust recovered and sold

- Economic parameters:

$M$ : unit cost of gross stone extraction $(\text { Euro } / t)^{6}$

$C_{g+1, g}$ : unit cost of crushing (Euro/t)

$K_{f}$ : unit cost of fuel $f($ Euro/TJ)

$T$ : unit external cost of landfill (Euro/t)

$H^{p}$ : unit external cost of pollutant $p($ Euro/t $)$

$P$ : market price of dust sold (Euro/t)

\section{The model}

We list the equations first, and comments follow. The objective consists of minimizing a generalized total operational cost (to be detailed below) with respect to the variables that determine this cost, and subject to meeting (i) the given demand level, (ii) the given capacities of the quarry and those of the plant, and (iii) given the existing technologies. Formally, this is expressed as the following problem:

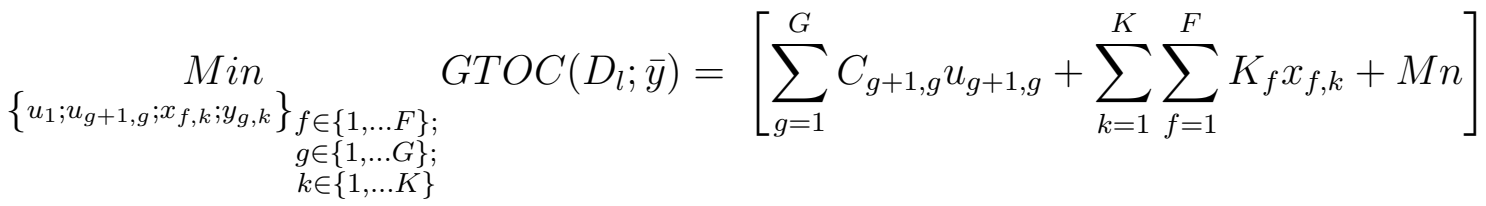

$$
\begin{aligned}
& +T\left[\sum_{g=1}^{G} v_{g}+(1-\xi) \sum_{k=1}^{K} w_{k}^{d}\right]+\sum_{k=1}^{K} \sum_{p=1}^{P} H^{p} w_{k}^{p}-\left[P \xi \sum_{k=1}^{K} w_{k}^{d}\right]
\end{aligned}
$$

\footnotetext{
${ }^{6} M$ also includes the opportunity cost expressing the fact that the producer wants to avoid the waste of his quarry.
} 
subject to the following constraints:

$$
\begin{aligned}
& n \leqslant N^{\max } \\
& q=\lambda n \\
& u_{g}=\alpha_{g} q, \forall g \\
& u_{g}+u_{g+1, g}=\sum_{k=1}^{K} \Omega_{g, k} y_{g, k}+v_{g}, \text { for } g=1 \\
& u_{g}+u_{g+1, g}-u_{g, g-1}=\sum_{k=1}^{K} \Omega_{g, k} y_{g, k}+v_{g}, \forall g \in[2, \ldots G-1[ \\
& u_{g}-u_{g, g-1}=\sum_{k=1}^{K} \Omega_{g, k} y_{g, k}+v_{g}, \text { for } g=G \\
& \sum_{g=1}^{G} \Omega_{g, k} y_{g, k} \leqslant \bar{Y}_{k}, \forall k \\
& \sum_{g=1}^{G} z_{g, k}=\varepsilon_{k} \sum_{f=1}^{F} \Psi_{f, k} x_{f, k}, \forall k \\
& z_{k, l}\left(1+\eta_{k}\right)=\left(1-\rho_{k}^{C O 2}\right) \Phi_{k, l} \sum_{g=1}^{G} y_{g, k}, \quad \forall k, l \\
& w_{k}^{p}=\sum_{f=1}^{F} \rho_{f}^{p} x_{f, k}, \forall k, \text { for } p=C O_{2}^{f}, S O_{2}^{f}, N O_{x}, C O \\
& w_{k}^{p}=\rho_{k}^{p} \sum_{g=1}^{G} y_{g, k}, \forall k, \text { for } p=C O_{2}^{p}, S O_{2}^{p} \\
& w_{k}^{d}=\eta_{k} \sum_{l=1}^{L} z_{k, l}, \forall k
\end{aligned}
$$




$$
\sum_{k=1}^{K} z_{k, l} \geqslant D_{l}, \forall l \in\{1, \ldots L\}
$$

The objective function (1) expresses the aggregate private and social cost that we advocate as a substitute to exclusively environmental considerations. The first bracketed terms are the private operational costs (costs of fuels, crushing and extraction $)^{7}$ whereas the remaining three bracketed terms are the external costs due to dust and gaseous emissions. The decision variables are those mentioned within braces under the Min operator.

The next thirteen equations describe the array of available techniques to produce $D_{l}$. Thus, equation (4) expresses the fact that a quarry is characterised by its usable limestone $(q)$ being distributed into $G$ categories of granulars, according to fractions $\alpha_{g}$. The quarry is characterized by a maximal gross flow capacity, denoted $N^{\max }$.

Equation (6) is essentially a material conservation relation applying to the type $g$ of granular obtained after an initial explosion. On the left hand side we have the stone $u_{g}$ coming directly from the quarry, plus $u_{g+1, g}$, the stone crushed from granular $g+1$ into granular $g$, minus $u_{g, g-1}$, the stone of granular $g$ crushed into the smaller category $g-1$. This flow is equal to the total amount of limestone put in kilns, $\sum_{k=1}^{K} \Omega_{g, k} y_{g, k}$, plus the residual $v_{g}$, not used for production and which goes to the landfill. This constraint does not hold for $g=1$ and $g=G$ since the variables $g(0)$ and $g(G+1)$ do not exist. In these two cases, the specific constraints (5) and (7) are relevant.

The capacity constraint of the plant, and so the one of each kiln, is assumed to be given. It is imposed by equation (8). Equation (9) specifies the fuel inputs $x_{f, k}$ needed to process the amount $\sum_{g=1}^{G} y_{g, k}$ loaded in each kiln $k$. Equation (10) specifies the total output $\left(z_{k, l}\right)$ of limestone of each quality $l$ obtained in kiln $k$, as determined by the technical coefficients $\Phi_{k, l}$.

\footnotetext{
${ }^{7}$ We thus implicitly assume that all the other costs (e.g. manpower, transportation, taxes) do not depend on the kiln use.
} 
The three following equations are devoted to discharges. The emissions of carbon dioxide resulting from fossil fuels combustion are given by equation (11) considering the carbon content of each fuel $\left(\rho_{f}^{p}\right)$. The other pollutants are related to the activity level of each kiln with the parameter $\rho_{k}^{p}$, as given in

equation (12). The quantity of dust emitted by each kiln $\left(w_{k}^{d}\right)$ is calculated using the output level of each kiln.

Finally, equation (14) ensures that, for each quality $l$, total output of lime meets at least the demand $D_{l}$.

As announced in the introduction, the solution of the linear programming problem (1)-(14) is the Best Combination of Available Techniques (BCAT) according to the criterion of the generalized (i.e. including private and environmental) total cost.

We now turn to a numerical illustration.

\section{Numerical values of the parameters}

The values of the parameters are gathered in Table 1 and briefly discussed in this section. Some of these values are specific to the plant or the technologies considered. Some others does not, but they may differ from on application to another for exogenous reasons (for example, fuels prices change every day). As a result, these values must be considered as illustrative.

We consider a quarry with a maximum gross flow of 3,000 kt of limestone per year. The proportion of usable stone is $90 \%$. Five kilns are available on the plant: one LRK, two SRKs and two PFRKs. The firm faces an exogenous demand of $1,150 \mathrm{ktCaO} /$ year. Only one quality category of lime is considered. 
Table 1: Parameter Values

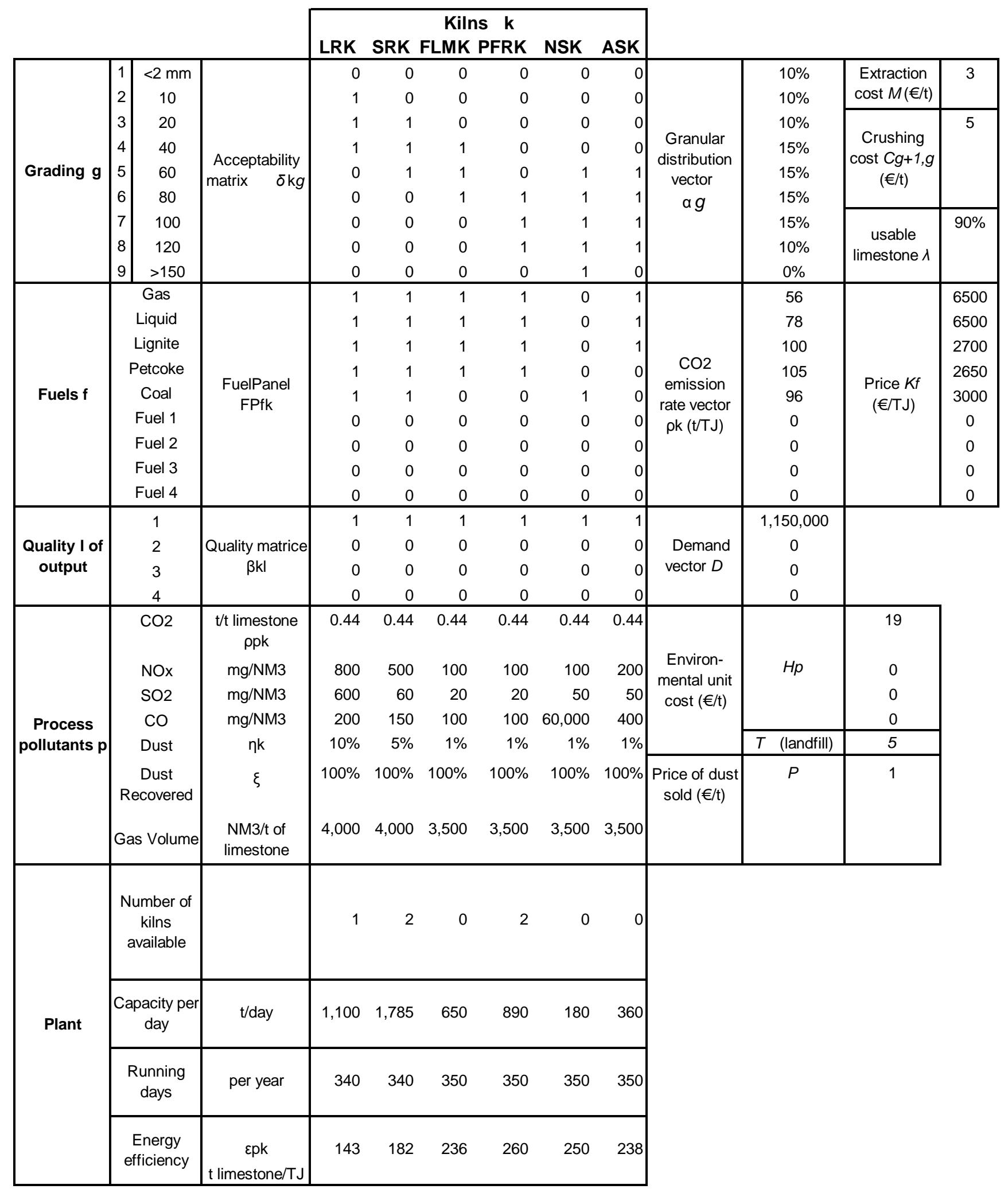


Each kiln is characterized by its technological features (input acceptability, fuel acceptability, energy efficiency, etc.): the values of the parameters for all these characteristics are standard and come from the BREF (reference document under the IPPC directive) as well as from discussions with specialists. We consider that all the dust is sold and without lost of generality, that the price for dust sold is 1 .

External costs are tricky to evaluate. To date, the main project devoted to these evaluations is the ExternE project undergone on behalf of the European Commission (see European Commission, 2005). An overview of this methodology is given in Appendix 1. In this paper we will focus on two pollutants having very distincts impacts ${ }^{8}$. The first one, carbon dioxide, is a global pollutant related to fuel combustion and process. The second one, the landfill, is a local pollutant related to the extraction activity and kiln feeding options. What is of particular interest here is to analyse how global and local pollutants may conflict at the plant level. As to carbon dioxide $(\mathrm{CO} 2)$, the benchmark value used in ExternE will be considered, which is 19 Euros/tCO2. The external cost of landfill will heavily depend on the location of the plant. As a preliminary value we shall retain 5 Euros/t. It must be stressed that, at this stage, all of these values require further explorations. The fact that large uncertainties remain be eluded and improving the methodology behind these figures is of major importance. In this paper we focus of the mechanisms, with figures to be interpreted as indicative only. Sensitivity analyses will be carried out hereafter on these values.

\section{The results (1): selecting a BCAT}

In line with the discussion above we consider two scenarios: a first one that determines a private optimum (hereafter, scenario A), a second one that computes a social optimum (hereafter, scenario B). The former scenario results from the minimization of the private costs only whereas the latter corresponds to the minimization of generalized costs, namely the private costs

\footnotetext{
${ }^{8}$ Dealing with more pollutants would be desirable and is feasible but it would make the results less transparent.
} 
plus the environmental (external) costs. Formally, to run out one scenario or another, we modify the objective function of our model (equation (1)), setting $H^{p}$ and $T$ equal to zero to obtain scenario A, while keeping their assumed positive values to get scenario B. For each of these scenarios we present the Best Combination of Available Techniques as it results from the optimization programme and we discuss the implications in terms of private, environmental and generalized costs.

\subsection{BCAT that minimizes private costs (P-BCAT)}

Table 2 displays the complete results (see on the following page). All figures are in tons per year, except for the costs at the bottom of the table which are in Euros/year.

Starting from the top of the Table, one may observe that the gross flow of limestone needed to face the demand is $2,649 \mathrm{kt} /$ year. The quantity of usable limestone is $2,384 \mathrm{kt} /$ year ( $90 \%$, by assumption). The amount of limestone of each granularity is given on line 10. Only limestone of granular 6 (60 to $80 \mathrm{~mm})$ is partially crushed $(330,606 \mathrm{t} /$ year among the 357,602 t/year available). No kiln can accept granular 1 . As a result, granular 1 goes to the landfill (line 12). The loading of each kiln is given in lines 16 to 24: we can see the amount of limestone entering each kiln (for example 238,402 tons of granular 2 limestone and 70,412 tons of granular 4 limestone are burnt in the LRK kiln). The kilns SRK and PFRK are used at full capacity (respectively $1,214 \mathrm{kt} /$ year and $623 \mathrm{kt} /$ year) and, not surprisingly, the finest limestone goes in LRK kiln (the utilization rate of the kiln is $82 \%$ ). Finally we see that petcoke, the cheapest fuel available, is used in all kilns (line 36).

Pollutants are reported in full detail. We distinguish $\mathrm{CO} 2$ emissions from process (line 47) and from fossil fuels combustion (line 48). The usual average emission rates prevail here: $1.6 \mathrm{tCO} 2 / \mathrm{tCaO}$ with the LRK, $1.4 \mathrm{tCO} 2 / \mathrm{tCaO}$ with the SRK and $1.2 \mathrm{t}$ with the PFRK kiln. Most of these emissions occur inside the kiln during the process $(55 \%, 60 \%$ and $67 \%$ respectively). For information, the emissions of $\mathrm{NO}_{x}, \mathrm{SO}_{2}$ and $\mathrm{CO}$ are given in line 50 to 52 . Dust emissions are completely captured into the filters and recovered (line 
Table 2: Private Optimum

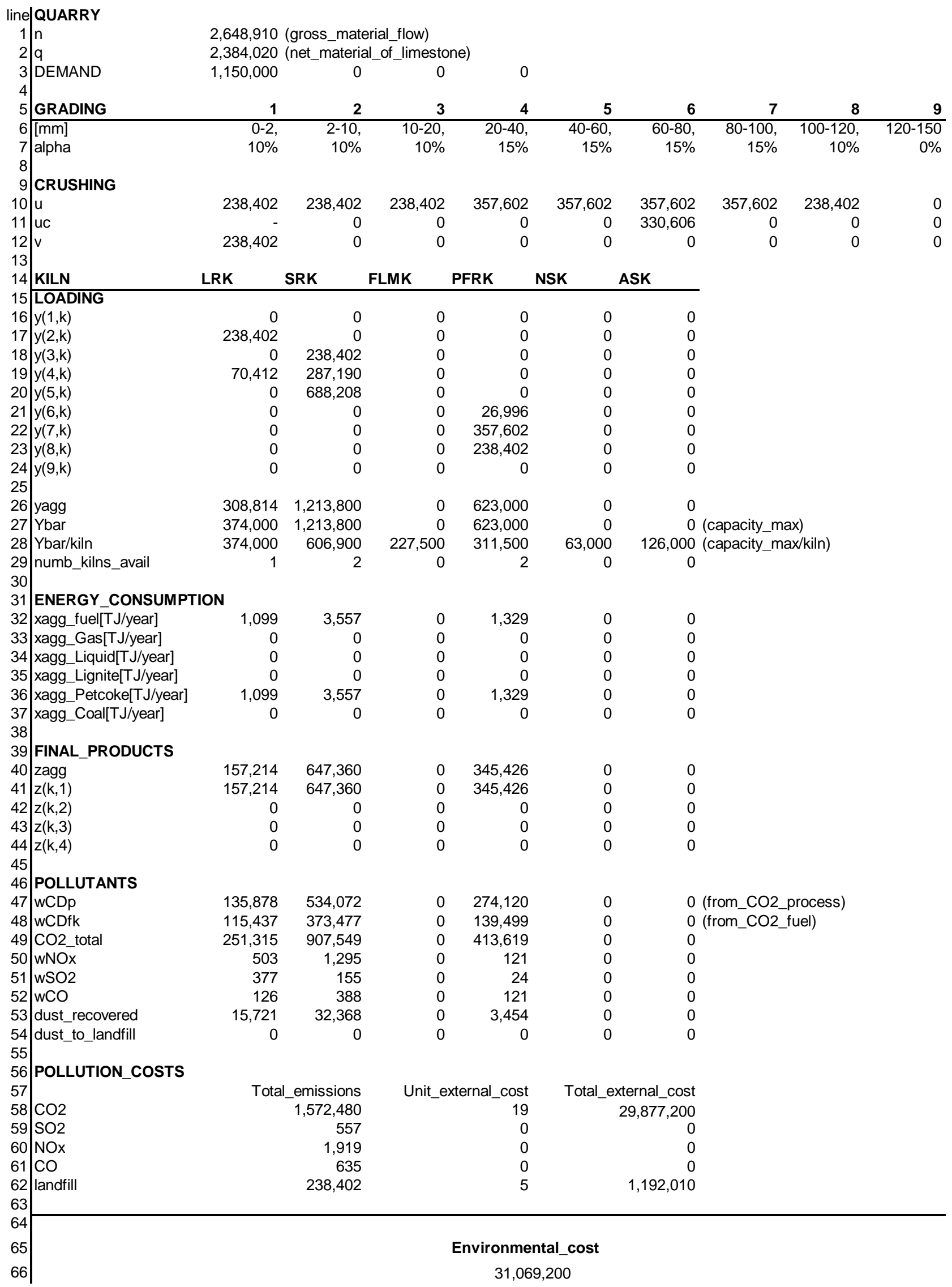


$53)$.

The last section of the Table displays the total emissions of each pollutant and the related total external costs. It appears that $\mathrm{CO} 2$ emissions constitute the major external cost: it amounts to $96 \%$ of the overall external cost of this plant ${ }^{9}$. With these two pollutants being considered, the total environmental cost reaches 31 million per year for this plant, which implies an average external cost of lime production of 26 Euros/tCaO.

To summarize this example, the privately best combination of available techniques (P-BCAT) for the plant to produce 1,150 kt of lime per year consists in extracting 2,649 $\mathrm{kt}$ of limestone, using a crushing set, using a LRK kiln at $82 \%$ capacity, using SRK and PFRK kilns at full capacity and using a single fuel, petcoke $(5,985$ TJ).

\subsection{BCAT that minimizes generalized costs (S-BCAT)}

The question addressed now is the following: when internalising external costs in a generalized cost function, what combination of techniques emerges and what social benefit may be expected? Our model allows us to illustrate numerically these two questions in the context of the industrial plant considered here. When introducing external costs in the objective function as an addition to the private costs, the algorithm yields the least-cost combination of techniques from society's point of view.

Table 3 displays the complete results for the social optimum.

What are the options for pollution abatement in the model? Basically, we can distinguish between emissions from fuels and emissions from the processes. The former can be reduced through fuel switch (for a given kiln). The latter cannot be reduced by kiln shift (for a given fuel) because, in our case, given the demand level, all the kilns available have to be used.

Like with the P-BCAT the least-cost solution consists of using the kilns SRK and PFRK at full capacity. Fuel switch depends on the relative price

\footnotetext{
${ }^{9}$ Let us recall that, to date, the external cost of the landfill is only indicative.
} 
Table 3: Social Optimum

\begin{tabular}{|c|c|c|c|c|c|c|c|c|c|c|}
\hline \multicolumn{11}{|c|}{ line|QUARRY } \\
\hline 1 & & \multicolumn{9}{|c|}{ 2,648,910 (gross_material_flow) } \\
\hline 2 & & \multicolumn{9}{|c|}{ 2,384,020 (net_material_of_limestone) } \\
\hline 3 & DEMAND & $1,150,000$ & 0 & 0 & 0 & \multirow[b]{2}{*}{5} & \multirow[b]{2}{*}{6} & \multirow[b]{2}{*}{7} & \multirow[b]{2}{*}{8} & \multirow{5}{*}{$\begin{array}{r}9 \\
120-150 \\
0 \%\end{array}$} \\
\hline 5 & GRADING & 1 & 2 & 3 & 4 & & & & & \\
\hline 6 & {$[\mathrm{~mm}]$} & $0-2$ & $2-10$ & $10-20$ & $20-40$ & \multirow{3}{*}{$\begin{array}{r}40-60 \\
15 \%\end{array}$} & \multirow{3}{*}{$\begin{array}{r}60-80, \\
15 \%\end{array}$} & 80-100, & \multirow{3}{*}{$\begin{array}{r}100-120 \\
10 \%\end{array}$} & \\
\hline 7 & alpha & $10 \%$ & $10 \%$ & $10 \%$ & $15 \%$ & & & $15 \%$ & & \\
\hline 8 & & & & & & & & & & \\
\hline 9 & CRUSHING & & & & & & & & & \\
\hline 10 & $\mathrm{u}$ & 238,402 & 238,402 & 238,402 & 357,602 & 357,602 & 357,602 & 357,602 & 238,402 & 0 \\
\hline 11 & uc & - & 0 & 0 & 0 & 0 & 330,606 & 0 & 0 & 0 \\
\hline 12 & v & 238,402 & 0 & 0 & 0 & 0 & 0 & 0 & 0 & 0 \\
\hline 13 & & & & & & & & & & \\
\hline 14 & KILN & LRK & SRK & LMK & FRK & ISK & ASK & & & \\
\hline 15 & LOADING & & & & & & & & & \\
\hline 16 & $y(1, k)$ & 0 & 0 & 0 & 0 & 0 & 0 & & & \\
\hline 17 & $y(2, k)$ & 238,402 & 0 & 0 & 0 & 0 & 0 & & & \\
\hline 18 & $y(3, k)$ & 0 & 238,402 & 0 & 0 & 0 & 0 & & & \\
\hline 19 & $y(4, k)$ & 70,412 & 287,190 & 0 & 0 & 0 & 0 & & & \\
\hline 20 & $y(5, k)$ & 0 & 688,208 & 0 & 0 & 0 & 0 & & & \\
\hline 21 & $y(6, k)$ & 0 & 0 & 0 & 26,996 & 0 & 0 & & & \\
\hline 22 & $y(7, k)$ & 0 & 0 & 0 & 357,602 & 0 & 0 & & & \\
\hline 23 & $y(8, k)$ & 0 & 0 & 0 & 238,402 & 0 & 0 & & & \\
\hline 24 & $y(9, k)$ & 0 & 0 & 0 & 0 & 0 & 0 & & & \\
\hline 25 & & & & & & & & & & \\
\hline 26 & yagg & 308,814 & $1,213,800$ & 0 & 623,000 & 0 & 0 & & & \\
\hline 27 & Ybar & 374,000 & $1,213,800$ & 0 & 623,000 & 0 & & (capacity_m & & \\
\hline 28 & Ybar/kiln & 374,000 & 606,900 & 227,500 & 311,500 & 63,000 & 126,000 & (capacity_m & ax/kiln) & \\
\hline 29 & numb_kilns_avail & 1 & 2 & 0 & 2 & 0 & 0 & & & \\
\hline 30 & & & & & & & & & & \\
\hline 31 & ENERGY_CONSUMPT & ION & & & & & & & & \\
\hline 32 & xagg_fuel[TJ/year] & 1,099 & 3,557 & 0 & 1,329 & 0 & 0 & & & \\
\hline 33 & xagg_Gas[TJ/year] & 0 & 0 & 0 & 0 & 0 & 0 & & & \\
\hline 34 & xagg_Liquid[TJ/year] & 0 & 0 & 0 & 0 & 0 & 0 & & & \\
\hline 35 & xagg_Lignite[TJ/year] & 1,099 & 3,557 & 0 & 1,329 & 0 & 0 & & & \\
\hline 36 & xagg_Petcoke[TJ/year] & 0 & 0 & 0 & 0 & 0 & 0 & & & \\
\hline 37 & xagg_Coal[TJ/year] & 0 & 0 & 0 & 0 & 0 & 0 & & & \\
\hline 38 & & & & & & & & & & \\
\hline 39 & FINAL_PRODUCTS & & & & & & & & & \\
\hline 40 & zagg & 157,214 & 647,360 & 0 & 345,426 & 0 & 0 & & & \\
\hline 41 & $\mathrm{z}(\mathrm{k}, 1)$ & 157,214 & 647,360 & 0 & 345,426 & 0 & 0 & & & \\
\hline 42 & $z(k, 2)$ & 0 & 0 & 0 & 0 & 0 & 0 & & & \\
\hline 43 & $z(k, 3)$ & 0 & 0 & 0 & 0 & 0 & 0 & & & \\
\hline 44 & $z(k, 4)$ & 0 & 0 & 0 & 0 & 0 & 0 & & & \\
\hline 45 & & & & & & & & & & \\
\hline 46 & POLLUTANTS & & & & & & & & & \\
\hline 47 & wCDp & 135,878 & 534,072 & 0 & 274,120 & 0 & & (from_CO2 & orocess) & \\
\hline 48 & wCDfk & 109,940 & 355,692 & 0 & 132,856 & 0 & 0 & (from_CO2 & uel) & \\
\hline 49 & CO2_total & 245,818 & 889,764 & 0 & 406,976 & 0 & 0 & & & \\
\hline 50 & wNOx & 503 & 1,295 & 0 & 121 & 0 & 0 & & & \\
\hline 51 & wSO2 & 377 & 155 & 0 & 24 & 0 & 0 & & & \\
\hline 52 & wCO & 126 & 388 & 0 & 121 & 0 & 0 & & & \\
\hline 53 & dust_recovered & 15,721 & 32,368 & 0 & 3,454 & 0 & 0 & & & \\
\hline 54 & dust_to_landfill & 0 & 0 & 0 & 0 & 0 & 0 & & & \\
\hline 55 & & & & & & & & & & \\
\hline 56 & POLLUTION_COSTS & & & & & & & & & \\
\hline 57 & & Total & emissions & Unit_ext & ernal_cost & Total_ex & ernal_cost & & & \\
\hline 58 & $\mathrm{CO} 2$ & & $1,542,560$ & & 19 & & $9,308,600$ & & & \\
\hline 59 & $\mathrm{SO} 2$ & & 557 & & 0 & & 0 & & & \\
\hline 60 & NOx & & 1,919 & & 0 & & 0 & & & \\
\hline 61 & $\mathrm{CO}$ & & 635 & & 0 & & 0 & & & \\
\hline 62 & landfill & & 238,402 & & 5 & & $1,192,010$ & & & \\
\hline 63 & & & & & & & & & & \\
\hline 64 & COSTS w.r.t. private o & ptimum & & & & & & & & \\
\hline $\begin{array}{l}65 \\
66\end{array}$ & & & & & & & & & & \\
\hline $\begin{array}{l}66 \\
67\end{array}$ & & $\begin{array}{l}\text { rivate_cost } \\
\Delta+1.2 \%\end{array}$ & & & nvironn & $\begin{array}{l}\text { tal_cost } \\
-1.8 \%\end{array}$ & & & $\begin{array}{l}\text { otal_cost } \\
-0 . \overline{5} \%\end{array}$ & \\
\hline
\end{tabular}


of fuels. Under private optimization the cheapest fuel (petcoke) was used in all kilns. However, this fuel is also the dirtiest in terms of $\mathrm{CO} 2$ emissions. As soon as its environmental cost is included and a social optimum is sought, the model chooses to burn a cleaner fuel, namely lignite in all kilns.

Let us point out that, in our model, the firm is assumed to satisfy demand. It follows that emission abatements by output reduction cannot occur. This holds for the process part of $\mathrm{CO} 2$ emissions.

Comparing private and social optima, it appears that the total private cost increases by $1.2 \%$ in scenario B with respect to scenario A whereas total external costs are reduced by $1.8 \%$. Overall, the social benefit resulting from the adoption of this combination of techniques is a decrease of the generalized cost by $0.5 \%$.

The socially best combination of available techniques (S-BCAT) for the plant considered to produce 1,150 kt of lime per year is obtained in this example as an extraction of 2,649 kt, a crushing set, a kiln use of LRK ( $82 \%$ capacity), SRK and PFRK (full capacity), and a fuel use of lignite (9,985 TJ). Total CO2 emissions decrease by $2 \%$ in comparison with the P-BCAT.

\subsection{Sensitivity analysis}

The social optimum just computed is in part determined by the unit external cost, $\mathrm{H}^{\mathrm{CO} 2}$, of carbon dioxide emissions. A sensitivity analysis bearing on this parameter shows that fuel switches occur as a result of increased values of $\mathrm{H}^{\mathrm{CO} 2}$. We have indeed the following fuel mixes at the successive social optima $^{10}$ :

- if $0<H^{C O 2}<10$, petcoke in all kilns;

- if $10 \leqslant H^{C O 2}<76$, lignite in all kilns;

- if $76 \leqslant H^{C O 2}<87$, coal in LRK and SRK, lignite in PFRK;

- if $87 \leqslant H^{C O 2}<88$, coal in LRK and SRK, gas in PFRK;

\footnotetext{
${ }^{10}$ These critical values are approximate in the sense that decimals are not given.
} 
- if $H^{C O 2} \geq 88$, gas in all kilns.

The carbon dioxide emissions occurring at the optimum for each level of $\mathrm{H}^{\mathrm{CO} 2}$ is depicted on Fig. 2 (Left). We see that the optimal emissions decrease with increases of $\mathrm{H}^{\mathrm{CO} 2}$. The resulting staircase shaped curve is to be interpreted as a marginal abatement cost curve of carbon dioxide for the plant.
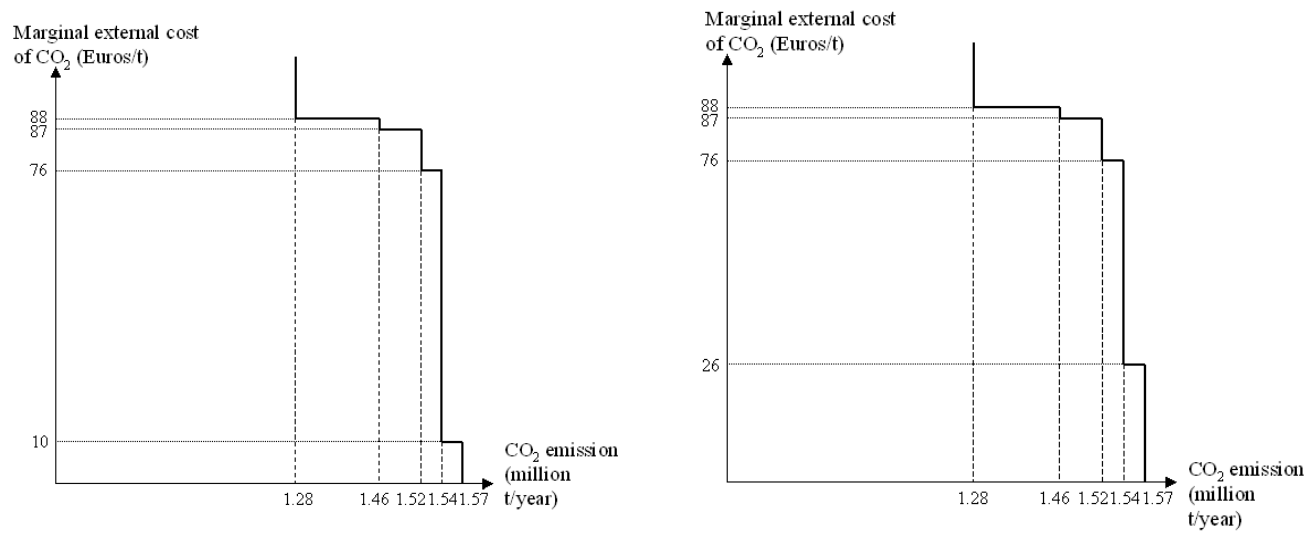

Figure 2: (Left) The marginal abatement cost curve for carbon dioxide. (Right) Influence of a $3 \%$ fall of the petcoke price on the $\mathrm{CO} 2$ marginal abatement cost curve.

The successive simulations also show that, as $H^{C O 2}$ is increasing, after each threshold, total private costs increase but total external costs decrease.

The shape of the marginal abatement cost curve is sensitive to the relative price of fuels. As an example, Fig. 2(Right) displays the same marginal abatement cost curve with a $3 \%$-lower petcoke price, all other things being equal. This shows that such a curve, while revealing technological constraints, is also dependent upon relative input prices.

Lastly, it is interesting to notice that imposing a tax above $€ 88$ does not further reduce $\mathrm{CO} 2$ emissions from that plant. 


\section{The results (2): BCATs as a function of external costs}

In this section we show that our methodology can be used to select the socially best combination of available techniques even when the plant capacity is not fixed. While the IPPC directive claims to define the socially optimal technique, our framework leads one to show that in most cases selecting a technology that consists in a single technique is not the best choice.

Consider the case where, given a quarry and its geological features (gross flow, granular...) and given a certain amount of demand to meet, the issue is to select the technology, that is, the combination of techniques that minimizes the generalized operational cost as defined above. Does the resulting S-BCAT consists in using a single kiln, or does it consist in using a combination of kilns?

The answer is obtained in the following way. For the sake of simplicity we limit our analysis to two contrasting pollutants: a local one, the landfill (whose unit external cost is denoted $T$ ), and a global one, carbon dioxide (whose unit external cost is denoted $\mathrm{H}^{\mathrm{CO} 2}$ ). For each configuration of the two unit external costs, taken over a range reasonably likely to be met in practice, we compute the optimal solution of the model (1) - (14) stated above, after deletion of the constraints (8) so as to reflect the present context of non fixed capacities. In each case, that is, for each couple of external costs, the solution yields the socially best combination of available techniques in terms of both the choice of kilns and the way to use them (crushing set and fuel use).

The outcome of the successive computations is conveniently presented in Fig. 3 where the $x$-axis measures $H^{C O 2}$ and the $y$-axis measures $T$. To each point of the space so defined there corresponds a numerical solution of the model, that is, an S-BCAT with free kilns choice expressed in terms of a combination of kilns and a profile of fuels uses.

The space is partitioned by continuous lines into three zones labeled I, II and III, with the respective optimal kiln combinations indicated in the 
Figure 3 : BCATs as a function of external costs

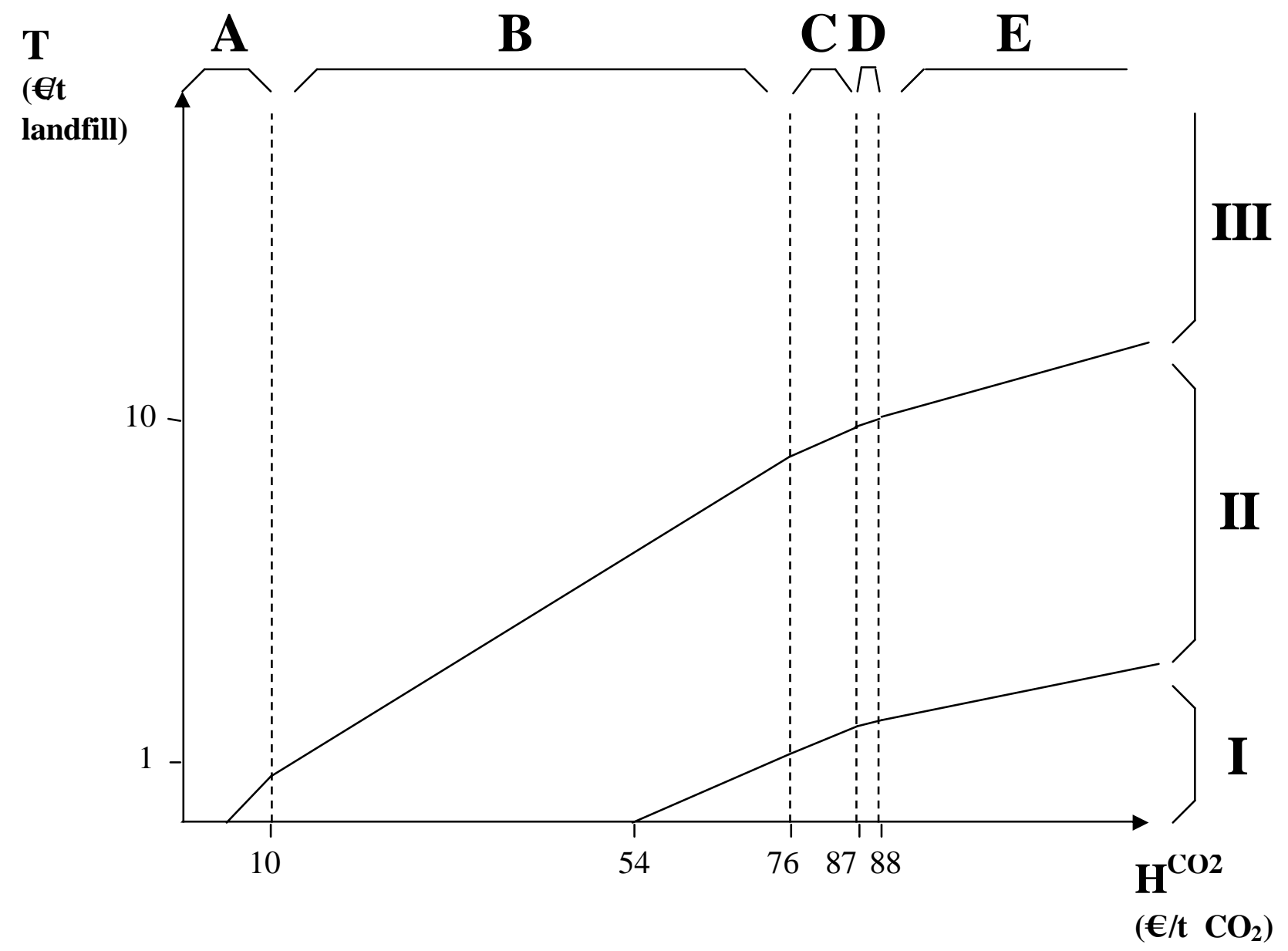

Table 4 : Legend to Figure 3

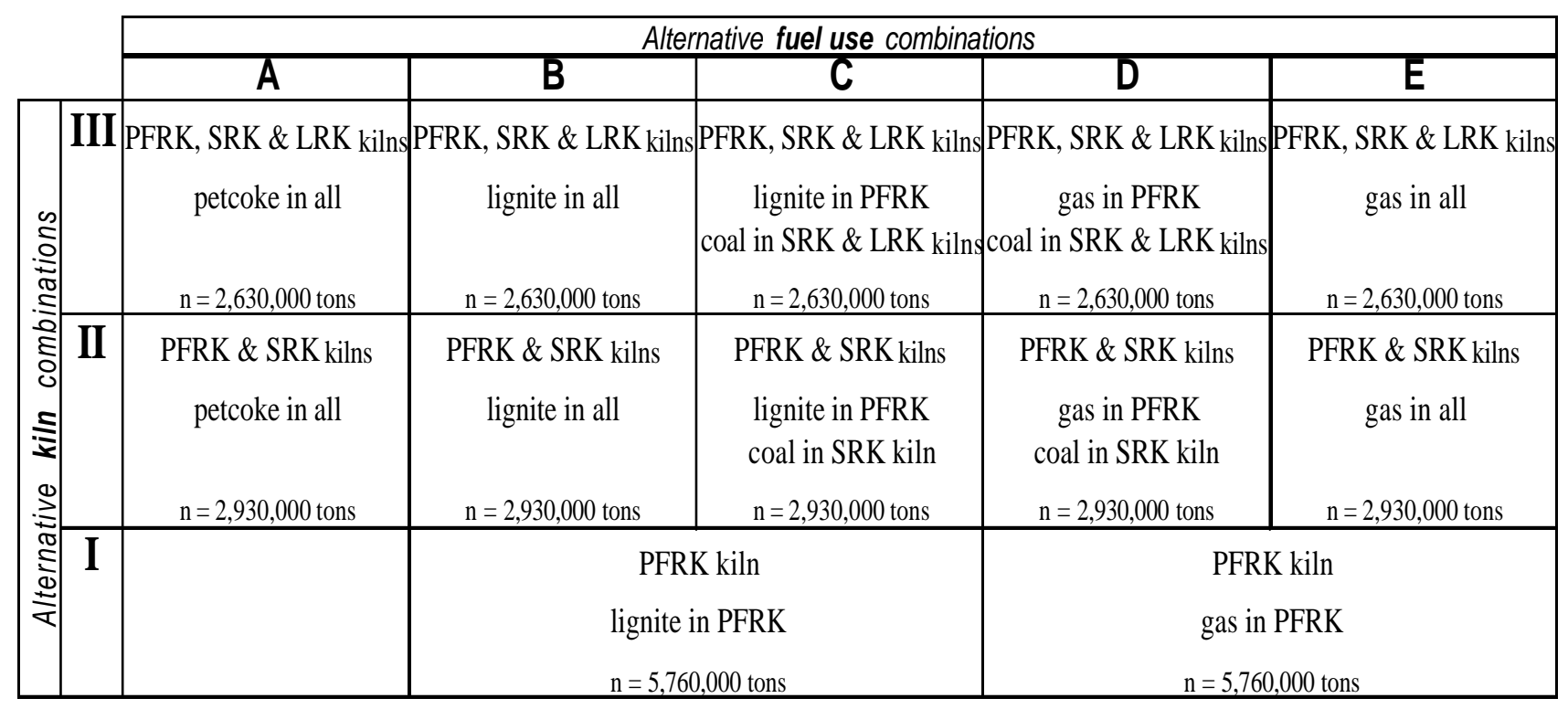


accompanying table (ignore momentarily the vertical dotted lines). The continuous lines that separate the zones reflect indifference (that is, equal total optimal operating cost) between the combinations induced by the points on either side. For the configurations of external costs that determine zone I, which is characterized by zero or very low level of the landfill unit external cost $T$ and a high level of $H^{C O 2}(\geq 54 € / \mathrm{t})$, the best combination of techniques is in fact a single technique: the PFRK kiln. For higher levels of the landfill unit cost $T$, the best combination is the mixed one of PFRK and SRK kilns. And for rather high values of $T$, LRK kilns also enter the optimal combination. In the table, one can see the values of $n$ (extraction of gross stone from the quarry) resulting from each kiln combinations. Note that the extraction required in zone I exceeds the assumed extraction capacity in our example (3,000 kt).

The above only describes alternative optimal kiln choices. However, the use of fuels with these kilns is also optimized within the model. This is illustrated by the dotted lines in Fig.3. As the fuels do not generate landfill environmental effects, the level of the associated external cost is nil. Only $\mathrm{CO} 2$ emissions matter. As the external unit cost $H^{C O 2}$ raises from zero to $88 € / \mathrm{t}$, optimal fuel uses with the appropriate kilns, switch from petcoke to lignite, to coal and then to gaseous fuel.

Taken together, the two partitionings just described of the $\mathrm{T}-\mathrm{H}^{\mathrm{CO} 2}$ space induces 12 zones, within each of which any point corresponds to an optimal choice of kilns, of the fuels to be used in them and of extraction and crushing activity. Thus for example, if the external cost of carbon dioxide is $80 € / \mathrm{t}$ and the external cost of the landfill is $10 € / \mathrm{t}$, then Fig.3 reveals that the BCAT plant is composed of the combination of three kinds of kilns (LRK, SRK and PFRK) operated jointly with a mix of fuels (lignite and coal). 


\section{Conclusion}

To cope appropriately with both the multi-dimensionality of technological choices and with the detrimental externalities that production can generate, we have developed a methodology to identify best available techniques from society's point of view. It consists of a comprehensive modeling tool based on linear programming of the productive operations and on internalization of the external costs generated by these operations. We conclude that in this context there is in general not a single best available technique (BAT), but well a best combination of available techniques to be used (BCAT).

¿From our example in the lime industry, let us underscore that when comparing the two scenarios (private and social) with fixed capacities there essentially appeared a drop of $2 \%$ in carbon dioxide emissions. Private total operating cost increased by $1.2 \%$ whereas external costs were reduced by $1.8 \%$. Overall, the social benefit resulting from the adoption of the best combination of techniques is a decrease of the generalized cost by $0.5 \%$.

This example illustrates the extent to which the internalization of the external costs can influence the choice of the techniques, that is, the very definition a $\mathrm{BAT}^{11}$. It further shows that the relation between the choice of kilns and the way to use them in terms of fuels choice does matter: good use of an existing technology can be as important as replacing it. Thus, the example identified that for certain structures of the external cost, switching to gas is preferable to kiln change. Finally, the example also showed that local conditions, as illustrated by the landfill external cost, do play a role no less important in socially best combination of techniques than global pollutants.

\footnotetext{
${ }^{11}$ It also confirms, yet in another context, a result put forward by Bréchet and Michel (2004) on environmental performance and equilibrium.
} 


\section{Appendix 1 : An overview of the ExternE Project}

External costs of emissions come from the ExternE (Externalities of Energy) project. For almost 15 years the European Commission has supported the development and application of a framework for assessing external costs of energy use. Researchers from all EU Members States have taken part. The main scope at this time has been the airborne pollutants from power plants and the development of the impact pathway approach. In fact, the ExternE project began in 1991 as the European part of a collaboration with the US Department of Energy in the EC/US fuel Cycles Study. The term fuel cycle refers to the chain of processes linked to the generation of electricity from a given fuel. For example, the assessment of the coal fuel cycle includes evaluation of the impacts associated with construction of new plant, coal mining, limestone quarrying (for flue gas desulphurisation, where used), transport of coal, wastes, other materials, power generation, waste disposal and electricity transmission. Damage assessments are carried out in the following areas: human health, building materials, crops, forests, freshwater fisheries and biodiversity.

The methodology may be applied at any industry level, but this is far from being straightforward. As soon as local pollutants are considered for a given industrial plant, local conditions under which this plant is running ought to be considered. Consequently, using the results from the ExternE study as such would be misleading. An extension of the methodology has been made and many results (as well as many others useful materials) are available on the web site of the Environment DG Bookshop ${ }^{12}$ and on the ExternE website $^{13}$. In particular, the last methodology update published ${ }^{14}$ includes assessment of the external costs for $\mathrm{SO}_{2}$ (sulphur dioxide), NOx (oxides of nitrogen) and PM (particulate matter). Externalities are calculated to give marginal figures. Health effects dominate.

A comprehensive description of these data is beyond the scope of this paper and is available on the web site given above. However, it is clear

\footnotetext{
${ }^{12}$ See http://europa.eu.int/comm/environment/enveco/studies2.htm

${ }^{13}$ See http://www.externe.info/

${ }^{14}$ See European Commission, Externalities of Energy, Methodology 2005 Update
} 
that, on the one hand, all the drawbacks of these figures must be kept in mind. The usefulness, inherent limitations and methodological shortcomings of these figures are discussed by Krewitt (2001), Eyre (1997) and Stirling (1997). 


\section{References}

[1] Backes Ch., Betlem G. (eds) (1999), Integrated Pollution Prevention and Control, the EC Directive from a Comparative Legal and Economic Perspective, Kluwer Law International, The Hague.

[2] Bréchet Th., Michel Ph. (2004), Environmental performance and equilibrium, CORE discussion paper 2004/72.

[3] Dijkmans R. (2000), Methodology for selection of best available techniques (BAT) at the sectoral level, Journal of Cleaner Production, 8, pp. 11-21.

[4] European Commission (1996), Council directive 96/61/EC of 24 September 1996 concerning Integrated Pollution Prevention and Control, OJ 1996 L 257/26.

[5] European Commission (2005), Externe, Externalities of Energy, Methodology 2005 Update.

[6] Eyre N. (1997), External costs : what do they mean for energy policy?, Energy Policy, Vol. 25, n.1, pp. 85-95.

[7] Faure M.G. and Lefevere J.G.J (1999), Integrated Pollution Prevention and Control: an economic appraisal, in: Backes Ch. and Betlem G. (eds), Integrated Pollution Prevention and Control, the EC Directive from a Comparative Legal and Economic Perspective, Kluwer Law International, The Hague, pp. 93-120.

[8] Geldermann J., Nunge S., Avci N., Rentz O. (2000), The Reference Installation Approach for the techno-economic assessment of emission abatement options and the determination of BAT according to the IPPC-Directive, French-German Institute for Environmental Research (DFIU / IFARE), University of Karlsruhe.

[9] Krewitt W. (2001), External costs of energy - do the answers match the questions? Looking back at 10 years of ExternE, Energy Policy, Vol. 30, n. 10, pp. 839-848. 
[10] Pearce D. (1993), The economics of technology-based environmental standards in: Helm D. (ed), Environmental Policy: objectives, instruments and implementation, Oxford, pp. 75-90.

[11] Smith A., Sorrel S. (2001), Interaction between environmental policy instruments: carbon emissions trading and Integrated Pollution Prevention and Control, International Journal of Environment and Pollution, Vol. 15, n. 1, pp. 22-41.

[12] Stirling A. (1997), Limits to the value of external costs, Energy Policy, Vol. 25, n. 5, pp. 517-540.

[13] Vercaemst P. (2002), BAT: when do best available techniques become Barely Affordable Technology?, Vito (Flemish Institute for Technological Research), IMS/N9109/PVc/02-26/V1, May. 
Département des Sciences Économiques de l'Université catholique de Louvain

Institut de Recherches Économiques et Sociales

Place Montesquieu, 3

1348 Louvain-la-Neuve, Belgique 